\title{
Genetic diversity in populations of Isatis glauca Aucher ex Boiss. ssp. from Central Anatolia in Turkey, as revealed by AFLP analysis
}

\author{
Özlem Özbek ${ }^{*}$, Elçin Görgülü ${ }^{1}$ and Şinasi Yıldırımlı
}

\begin{abstract}
Background: Isatidae L. is a complex and systematically difficult genus in Brassicaceae. The genus displays great morphological polymorphism, which makes the classification of species and subspecies difficult as it is observed in Isatis glauca Aucher ex Boiss. The aim of this study is characterization of the genetic diversity in subspecies of Isatis glauca Aucher ex Boiss. distributed widely in Central Anatolia, in Turkey by using Amplified Fragment Length Polymorphism (AFLP) technique.

Results: Eight different EcoRI-Msel primer combinations produced 805 AFLP loci, 793 (98.5\%) of which were polymorphic in 67 accessions representing nine different populations. The data obtained by AFLP was computed with using GDA (Genetic Data Analysis) and STRUCTURE (version 2.3.3) software programs for population genetics. The mean proportion of the polymorphic locus $(P)$, the mean number of alleles $(A)$, the number of unique alleles $(U)$ and the mean value of gene diversity $(H e)$ were $0.59,1.59,20$, and 0.23 respectively. The coancestry coefficient $(\Theta)$ was 0.24 . The optimal number of $K$ was identified as seven. The principal component analysis (PCA) explained $85.61 \%$ of the total genetic variation.
\end{abstract}

Conclusion: Isatis glauca ssp. populations showed a high level of genetic diversity, and the AFLP analysis revealed that high polymorphism and differentiated subspecies could be used conveniently for population genetic studies. The principal coordinate analysis (PCOA) based on the dissimilarity matrix, the dendrogram drawn with UPGMA method and STRUCTURE cluster analysis distinguished the accessions successfully. The accessions formed distinctive population structures for populations $A A, A B, E, K$, and $S$. Populations $A G 1$ and $A G 2$ seemed to have similar genetic content, in addition, in both populations several hybrid individuals were observed. The accessions did not formed distinctive population structures for both populations Al and ANP. Consequently, Ankara province might be the area, where species Isatis glauca Aucher ex Boiss. originated.

Keywords: AFLP; Genetic diversity; Isatis glauca subspecies; ssp. galatica; ssp. glauca; ssp. sivasica

\section{Background}

Isatis glauca Aucher ex Boiss., is a diploid biennial or perennial herbaceous species with a chromosome number set of $14(2 \mathrm{n}=28)$. Isatis glauca has four recognized subspecies, glauca, galatica Yıldırıml, sivasica (Davis) Yldırımlı and iconia (Boiss.) Davis. The distribution of this polymorphic species in Turkey is represented in Figure 1 (Yildırımlı 1988).

\footnotetext{
* Correspondence: ozbekozlem@gmail.com

${ }^{1}$ Department of Biology, Faculty of Art and Science, Hitit University, Ulukavak Mah. Çiftlik Çayııı Cd. No: 61, Çorum, Turkey

Full list of author information is available at the end of the article
}

Taxonomic and cytological investigations on the Isatis L., species grown in the Eastern and South Eastern Anatolia and across the Eastern Mediterranean region were made by Misirdalı (1985) (Figure 1, the region on the left side of red diagonal line on the map of Turkey). Misirdalı (1985) displayed that there were 31 species, 14 subspecies, and 2 varieties in Isatis collections from East \& Southeast Anatolia, and the Eastern Mediterranean - regions in Turkey. Yıldırımlı and Doğan (1986) investigated palynological polymorphism in 790 pollen grains collected from Isatis glauca ssp. glauca flowers in Sivas province of Turkey. They observed that 505 (62.92\%) of those pollen grains were tricolpate (normal), 129 (16.33\%) were syn- 


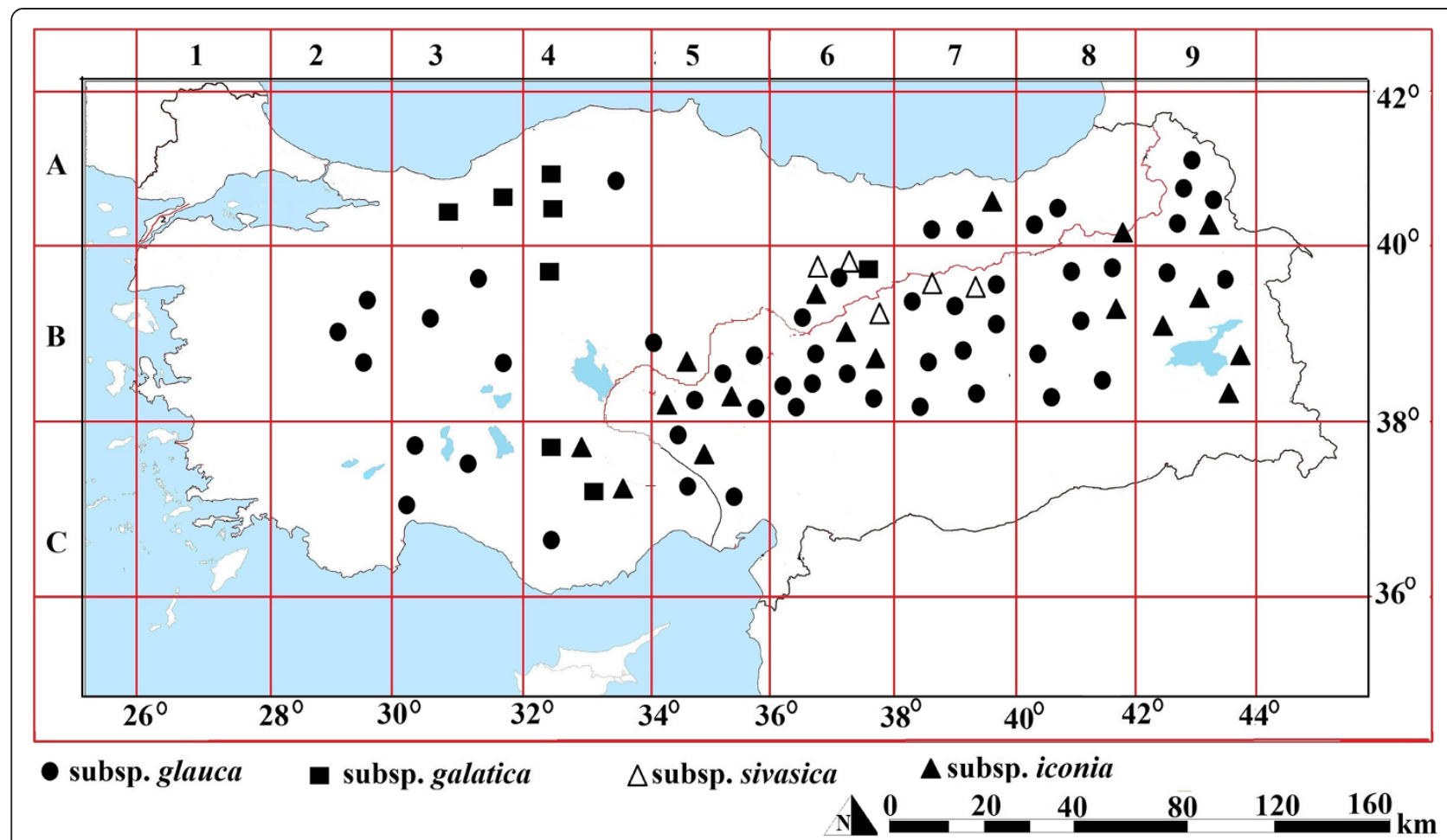

Figure 1 Distribution of Isatis glauca Aucher ex Boiss. subspecies in Turkey. The subspecies on the right side of the diogonal line were reported by Mısırdalı (1985) and the subspecies on the left side of the diogonal line were reported by Yıldırımlı (1988).

colpate, $87(11.01 \%)$ were stefanocolpate and $69(8.73 \%)$ were dicolpate. Gilbert et al. (2002) screened genetic diversity in Isatis ssp. (Isatis tinctoria L., dyer's woad) by using AFLP. Al-Shehbaz et al. (2006) discussed the evaluation of characters and their utilisation in infrafamilial classifications, delimitations of genera, the collection of molecular data and major subdivisions of the family, problematic taxa and future challenges in the Brassicaceae (Cruciferae). Kizll (2006) reported morphological and agronomical characteristics of some wild and cultivated Isatis species. Moazzeni and Zarre (2006) studied the presence of Isatis tinctoria in Iran by using its morphological characters. Moazzeni et al. (2007) examined the systematic application of seed-coat surfaces of 23 species (41 populations) in four genera of tribe Isatidae using scanning electron microscopy (SEM). Spataro et al. (2007) displayed genetic variation and population structure in a Eurasian collection of Isatis tinctoria L. by using AFLP and SAMPL molecular markers. Spataro and Negri (2008) analysed phenotypic and genetic diversity of a Eurasian collection of Isatis tinctoria as well as its adaptability according to a wide range of altitudes. Tu et al. (2008) assessed intertribal somatic hybrids between Brassica rapa and Raphanus sativus with dye and medicinal plant Isatis indigotica. Du et al. (2009) presented the production and cytogenetic characterisation of intertribal somatic hybrids between Brassica napus and Isatis indigotica, and backcrosses. Tu et al. (2009) showed the chromosome elimination, addition, and introgression in intertribal partial hybrids between Brassica rapa and Isatis indigotica. Moazzeni et al. (2010) analysed the phylogeny of 28 Iranian taxa of Isatidae by using ITS sequence of ribosomal DNA and morphological characters. Rocha et al. (2011) detected genetic diversity in woad (Isatis tinctoria L.) by using ISSR markers. All these studies reveal that although there are many reports on morphological and genetic variation in the Brassicaceae family, very few studies are found on morphological or genetic variation in Isatis glauca Aucher ex Boiss.

The aim of this study was to analyse genetic diversity and population structure using molecular marker techniques among the I. glauca, subspecies populations from Central Anatolia in Turkey. AFLP method was used to estimate genetic diversity $(\mathrm{He})$, population structure and genetic differentiation between populations using coancestry coefficient $\Theta_{\mathrm{P}}\left(=F_{\mathrm{ST}}\right)$. In addition, the study also aimed to find the effects of climate (temperature $T$, humidity $H U$, and rainfall $R$ ), and geography (altitudes $A L$, latitudes $L A$ and longitudes $L N$ ) on the genetic diversity of nine I. glauca populations.

\section{Materials and Methods}

Materials

In this study, genetic diversity of 67 accessions from nine I. glauca subspecies populations collected from Ankara/ 
Ayas (AA), Ankara/Beytepe (AB) valley, Ankara/Incek (AI), Ankara/Golbasi1 (AG1), Ankara/Golbasi2 (AG2), Ankara/Polatlı (ANP), Eskisehir (E), Konya (K) and Sivas (S) (Figure 2) in May and July of 2011. For amplified fragment length polymorphism (AFLP) analysis, one individual was used from each accession. The Additional file 1: Table S1 contains also population codes (PC), accession numbers (AN), and subspecies names. Throughout the text, the different populations were identified based on those codes. Plant specimens, are kept in Hacettepe University Herbarium (HUB) and identified by Prof. Dr. Şinasi Yıldırıml.

\section{Methods}

\section{Fluorescent based AFLP analysis}

Genomic DNA was extracted from 1 to 1.5 month old leaves of individual plants from each of 67 accession using CTAB method, as described by Kidwell and Osborn (1992). AFLP analysis was carried out as described by Vos et al. (1995), with minor modifications. The primers, adaptors, and altogether, eight primer combinations used in this study are given in Additional file 2: Table S2 and Additional file 3: Table S3 respectively.

\section{Restriction-ligation reaction}

The aliquots of the restriction-ligation master-mix (a-RLMM) were prepared in a $2 \mathrm{~mL}$ Eppendorf tube without enzymes and the T4 DNA ligase buffer 10x. In arestriction-ligation master-mix (RLMM) for one sample, the following were added; $0.617 \mu \mathrm{L} \mathrm{H} 2 \mathrm{O}, 1.1 \mu \mathrm{L} \mathrm{NaCl}(0.5 \mathrm{M})$, $0.55 \mu \mathrm{L}$ BSA $10 \times(1 \mathrm{~g} / \mathrm{L}), 1 \mu \mathrm{L}$ Mse I adaptor $(50 \mathrm{pmol} / \mu \mathrm{L}=$
$50 \mu \mathrm{M})$ and $1 \mu \mathrm{L} E c o \mathrm{R}$ I adaptor $(5 \mathrm{pmol} / \mathrm{L}=5 \mu \mathrm{M})$. The RLMM was prepared by using $1.1 \mu \mathrm{L}$ aliquots T4 DNA ligase buffer 10x, $4.267 \mu \mathrm{L}$ a-RLMM, $0.05 \mu \mathrm{L}$ Mse I (20 U/ $\mu \mathrm{L})$ enzyme, $0.05 \mu \mathrm{L}$ EcoR I (100 U/ $\mu \mathrm{L})$ enzyme, and $0.033 \mu \mathrm{L}$ T4 DNA ligase enzyme (30 weissU/ $\mu \mathrm{L}$ ). 96 well PCR microtiter plates were used for 67 samples. For each sample a $5.5 \mu \mathrm{L}$ RLMM aliquot was dispensed into the wells and the $5.5 \mu \mathrm{L}$ of the diluted sample genomic DNA (50 ng) was added. PCR microtiter plates were short spinned in a centrifuge (Sigma 1-14) and left for incubation (Techne $\mathrm{TC}-412)$ at $37^{\circ} \mathrm{C}$ for 6 hours.

\section{Preselective PCR amplification}

Before the preselective PCR amplification, the $5-\mu \mathrm{L}$ restriction-ligation products were diluted by adding $95 \mu \mathrm{L}$ TE (1X). For the preselective PCR amplification, the primers, were complementary to the sequences of the EcoR I and Mse 1 adaptors, that contained one selective nucleotide. Preselective PCR, reaction consisted of $2 \mu \mathrm{L}$ (10X) PCR buffer, $1.6 \mu \mathrm{L}(2 \mathrm{mM}) \mathrm{MgCl}_{2}, 1.2 \mu \mathrm{L}(2.5 \mathrm{mM})$ dNTPs, $1 \mu \mathrm{L}$ (5 pmol) EcoR I primer, $1 \mu \mathrm{L}$ (5 pmol) Mse I primer, $0.2 \mu \mathrm{L}(1 \mu / \mu \mathrm{L})$ Taq DNA polymerase, $9 \mu \mathrm{L}$ $\mathrm{ddH}_{2} \mathrm{O}$, and $4 \mu \mathrm{L}$ diluted restriction-ligation products. The diluted restriction-ligation products were kept at $-20^{\circ} \mathrm{C}$ until used. Preselective amplification for 20 cycles was carried out through PCR. Initial extended denaturation was carried out at $94^{\circ} \mathrm{C}$ for $2 \mathrm{~min}$, followed by denaturation at $94^{\circ} \mathrm{C}$ for $30 \mathrm{sec}$, annealing at $56^{\circ} \mathrm{C}$ for $30 \mathrm{sec}$, extension at $72^{\circ} \mathrm{C}$ for $2 \mathrm{~min}$, and the final extension at $60^{\circ} \mathrm{C}$ for $30 \mathrm{~min}$.

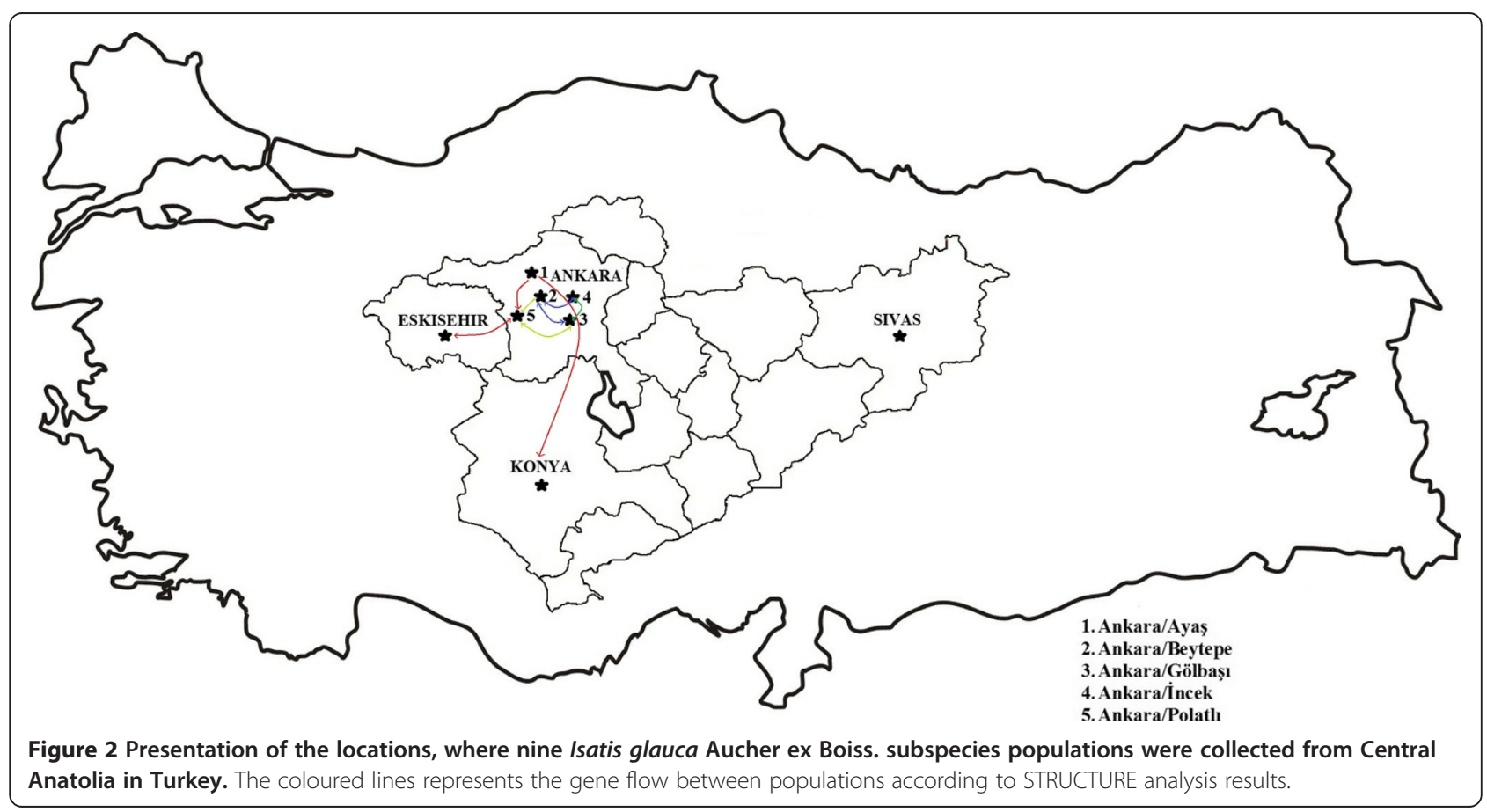




\section{Selective PCR amplification}

Selective PCR amplification was carried out using $10 \mu \mathrm{L}$ preselective PCR amplification products diluted in $190 \mu \mathrm{L}$ TE (1X). The diluted preselective PCR amplification products were kept at $-20^{\circ} \mathrm{C}$ until used. The selective PCR amplification was done with EcoR I and Mse I primers, which contained three selective nucleotides. For the fluorescent-based fragment analysis, the EcoR I selective primers of 39, 36, 39, and 36 were labelled with FAM-1, FAM-2, FAM-3, and FAM-4 respectively, while the EcoR I selective primers $33,36,33$, and 36 were labelled with VIC-1, VIC-2, VIC-3, and VIC-4 fluorescent dye. Mse I primers were used with the unlabelled ones. The selective PCR amplification used in this study is given in Additional file 4: Table S4.

\section{Capillary electrophoresis}

Capillary electrophoresis of selective amplification products were performed by using ABI $3130 \times 1$ (Applied Biosytems Inc., Foster City, CA). For capillary electrophoresis; $1 \mu \mathrm{L}$ selective PCR amplification products were denatured using $0.2 \mu \mathrm{L}$ LIZ-500 size standard at $95^{\circ} \mathrm{C}$ for $5 \mathrm{~min}$ followed by heat shock applied by chilling on ice at $0^{\circ} \mathrm{C}$ for $5 \mathrm{~min}$. Then, permanently denatured single stranded DNA was loaded on ABI $3130 \mathrm{X}$ l. After capillary electrophoresis, AFLP fragments were scored into a binary data matrix as 1 (present) or 0 (absent) using Gene Mapper 4.0 software package (Applied Biosystems).

\section{Statistical analysis}

For investigation of population structures of nine $I$. glauca ssp. populations, we used the software program STRUCTURE (Pritchard et al. 2000). STRUCTURE provides a model-based Bayesian approach to explain population structure by using our entire AFLP markers data set to identify $K$ clusters to which the program then assigns each individual. We used 67 individuals to infer the optimal value of $K$ (ie., the number of clusters) by evaluating $K=1-9$. For parameter set, in our model, we selected with admixture as ancestry model and the allele frequencies were assumed to be correlated, since it is more reasonable to assume common ancestry of such closely related populations. The length of burn-in Markov Chain Monte Carlo (MCMC) replications was set to 10000 and data were collected over 100000 MCMC replications in run, based on previous literature suggesting that this level is sufficient (Evanno et al. 2005). We determined the optimal value of $K$ using the second order statistics $(\Delta \mathrm{K})$ developed by Evanno et al. (2005) and the ad hoc procedure described by Pritchard et al. (2000).

To confirm the results obtained from STRUCTURE, we conducted two additional analyses enabling us to visualise distribution of individuals. First, we performed Principal Coordinate Analysis (PCoA). PCoA is a scaling or ordination method that starts with a matrix of similarities or dissimilarities between a set of individuals. The method aims to produce a low-dimensional graphical plot of the data in such a way that distances between the points in the plot are close to the original dissimilarities. For PCoA, the dissimilarity matrix values were used to ordinate 67 accessions representing nine Turkish Isatis glauca subspecies populations on a scattered plot using XLSTAT (version 2013, Addinsoft ${ }^{\mathrm{tm}}$ ), a software package for Windows (Figure 3). Second, a dendrogram (Figure 4) was constructed according to Nei's (1978) genetic distance and UPGMA method using the software program GDA (Genetic Data Analysis; Lewis and Zaykin 2001) version 1.1., which is a software package for analysis of discrete population genetics data according to Weir (1996).

\section{Principal component analysis (PCA)}

PCA was calculated by using the following genetic indices, and the sample sizes: $P, A$ and $H e$, and $N$ respectively, as well as geographical $(A L, L A$, and $L N)$ and climatic $(R A, T$, and $H U$ ) data (Additional file 5: Table S5) as variables according to the Pearson's (one-tailed) correlation matrix using XLSTAT (version 2013, Addinsoft ${ }^{\mathrm{tm}}$ ) a software package for Windows.

Since AFLPs are dominant markers, data were scored as binary data. Polymorphic bands, exhibiting presence or absence of bands, were scored as alternative alleles. The data thus obtained were considered as haploid and analysed by GDA.

Gene diversity ( $\mathrm{He}$ ) (Nei 1973), estimating withinpopulation diversity, was computed as the expected heterozygosity based on allele frequencies for each locus and for all loci, polymorphic and non-polymorphic ones.

Genetic differentiation between populations is often estimated with the Nei's coefficient $G_{\mathrm{ST}}$ (Nei 1973) for dominantly inherited DNA markers. This coefficient may tell us how genetic variation is partitioned within- and between-populations; a high $G_{S T}$ value indicates that plants within a population are relatively similar, but populations are considerably different. When there are two alleles ( 1 and 0$)$, this $G_{\mathrm{ST}}$ is identical to Wright's (1951) $F_{\mathrm{ST}}$ (Nei 1973). Thus, $F$ statistics was used to estimate the extent of differentiation, between groups (populations and sub-populations) (Hartl and Clark 1997). The coancestry coefficient $\Theta\left(=F_{\mathrm{ST}}\right)$ was measured for every locus and for all loci in each population.

Multiple regression analysis (MR) (SPSS version 11 for Windows) was conducted with AFLP diversity and allele diversity in nine populations. MR employed the genetic variables $(P, A$ and $H e)$ as dependent and the environmental variables $(A L, L A, L N, R A, T$, and $H U)$ as independent. 


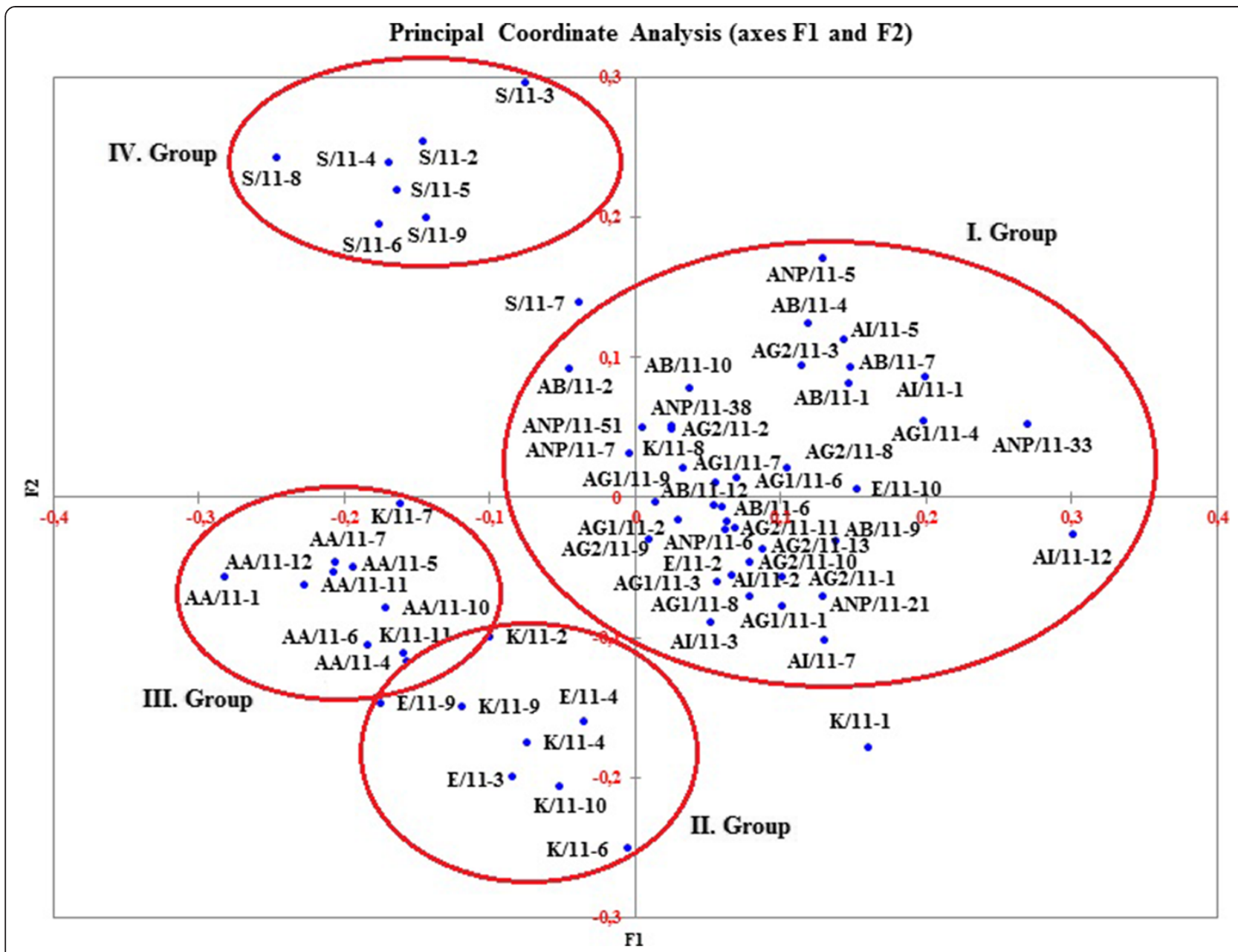

Figure 3 The scattered plot of the first and second principal coordinates obtained from eight AFLP primer combinations in 67 accessions from nine Isatis glauca Aucher ex Boiss. subspecies populations.

\section{Reproducibility of AFLP profiles}

The reproducibility of scoring of the AFLP profiles was checked by analysing the genotyping error rate in repeated runs of the same extracts from eight plants. In the beginning of the study, 12 different primer combinations were scanned for eight samples (accessions) and the eight polymorphic primer sets selected and applied for all of the 67 accessions. The data were obtained using selected eight primer combinations in both pre-scanning and applied through all accessions including those eight accessions were compared to evaluate the reproducibility of AFLP markers. The percent of reproducibility was calculated for each primer combination. Average percent of reproducibility was calculated as $90.62 \%$ that ranged $86.38 \%$ (E36XM35) to 97.78\% (E36XM34) among the primer combinations.

\section{Results}

\section{AFLP fragment analysis}

In AFLP analysis, eight EcoR I and Mse I primer combinations generated 805 fragments. The primer combination
E36xM34 produced the highest number (194) of fragments, while the primer combination E36xM33 produced the least number (32) of fragments (data not shown). The primer combination E36xM34 displayed the highest number (510) of fragments in population AA in total of eight individuals, while the primer combination E39xM41 displayed the least number (81) of fragments in population AI in total of six individuals. Average number of fragments per population was calculated according to total present fragment numbers produced by eight primer combinations in all individuals of each population and ranged 252.17 (in population $\mathrm{AI}$ ) to 314.75 (in population AA).

\section{Genetic analysis}

In AFLP analysis, eight EcoR I and Mse I primer combinations produced 805 fragments (loci), 793 (98.5\%) of which were polymorphic and $12(1.5 \%)$ were monomorphic. The proportion of the mean number of the polymorphic loci $(P=0.59)$, the mean number of alleles $(A=1.59)$ and the 


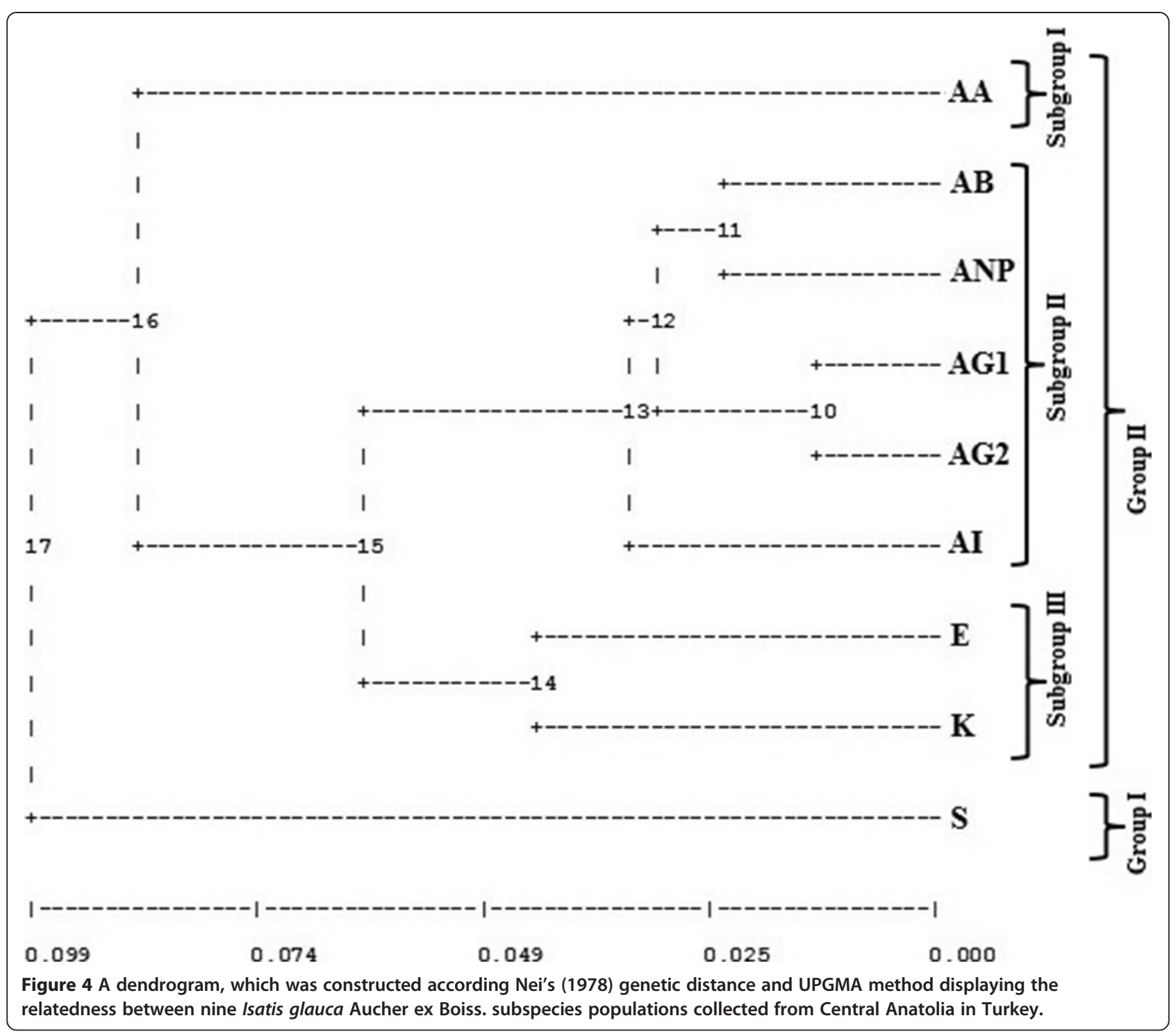

mean value of the genetic diversity $(\mathrm{He}=0.23)$ for nine populations, are represented in Table 1 . Population $\mathrm{K}$ has the highest proportion of polymorphic loci $(P=$ $0.68)$, the highest number of alleles $(A=1.68)$, and the highest value $(\mathrm{He}=0.26)$ of genetic diversity (Table 1 ). Population AI has the lowest proportion of polymorphic loci $(P=0.50)$ and the lowest number of alleles $(A=1.5)$, while population $\mathrm{S}$ has the lowest genetic diversity value $(H e=0.20)$.

The mean value of the coancestry coefficient $\Theta\left(=F_{\mathrm{ST}}\right)$ or genetic differentiation between the populations is 0.24 (95\% confidence interval) (Table 1). The highest genetic distance $(G D=0.24)$ was observed between population $\mathrm{AA}$ and population $\mathrm{S}$, while the lowest genetic distance $(G D=0.04)$ was observed between AG1 and AG2 (Data not shown).

\section{Unique alleles}

In AFLP analysis of nine I. glauca ssp. populations, 19 unique alleles were observed (Additional file 6: Table S6). About the unique alleles, two existed in population AA, 1 in each of populations AG1 and E, 3 in population AG2 and 12 in population $\mathrm{S}$. The frequencies of unique alleles range 0.13 (in populations AG1, AG2 and S) to 1.00 (population S).

\section{Population structure}

The second order statistics developed by Evanno (2005) for STRUCTURE in order to determine the number of subpopulations identified the optimal value for $K=7$ (Figure 5). It was confirmed by also the ad hoc procedure (Figure 6) developed by Pritchard et al. (2000). This means that the set of accessions was partitioned into 
Table 1 The number of sample size $(N)$, the proportion of polymorphic locus $(P)$, number of alleles $(A)$, the genetic diversity value $(\mathrm{He}$ ) and unique allele $(U)$ numbers per population, and coancestry coefficient $(\theta)$ for studied nine Turkish Isatis glauca subspecies populations

\begin{tabular}{lllllll}
\hline POP & $\boldsymbol{N}$ & $\boldsymbol{P}$ & $\boldsymbol{A}$ & $\boldsymbol{H e}$ & $\boldsymbol{U}$ & $\boldsymbol{\theta}$ \\
\hline AA & 8 & 0.60 & 1.60 & 0.22 & 2 & \\
AB & 8 & 0.60 & 1.60 & 0.22 & - & \\
AG1 & 8 & 0.58 & 1.58 & 0.21 & 1 & \\
AG2 & 8 & 0.61 & 1.61 & 0.23 & 3 & \\
Al & 6 & 0.50 & 1.50 & 0.22 & - & \\
ANP & 7 & 0.60 & 1.60 & 0.23 & - & \\
E & 5 & 0.56 & 1.56 & 0.25 & 1 & \\
K & 9 & 0.68 & 1.68 & 0.26 & - & \\
S & 8 & 0.54 & 1.54 & 0.20 & 12 & \\
Mean & & 0.59 & 1.59 & 0.23 & & 0.24 \\
\hline
\end{tabular}

seven clusters, which corresponded to the ssp. galatica, ssp. glauca and ssp. sivasica. When the coloured individual bar plot (Figure 7) was examined, some accessions had varying proportions of their genome from other clusters.

Accessions formed distinctive population structures for populations AA, AB, E, K, and S. Populations AG1 and AG2 seemed to have similar genetic content, in addition in both populations several hybrid individuals were observed. Populations AI and ANP did not display distinctive population structures. In these populations, all individuals, except one individual in population AI, were seemed to be hybrids. In general, all populations have hybrid individuals.

The hybrid individuals detected in this study is an indication of gene flow between populations. Particularly, extensive gene flow was observed between AG1, AG2, $\mathrm{AI}$, and ANP. It is noteworthy that there is a population (light green colour) found in hybrid individuals, although

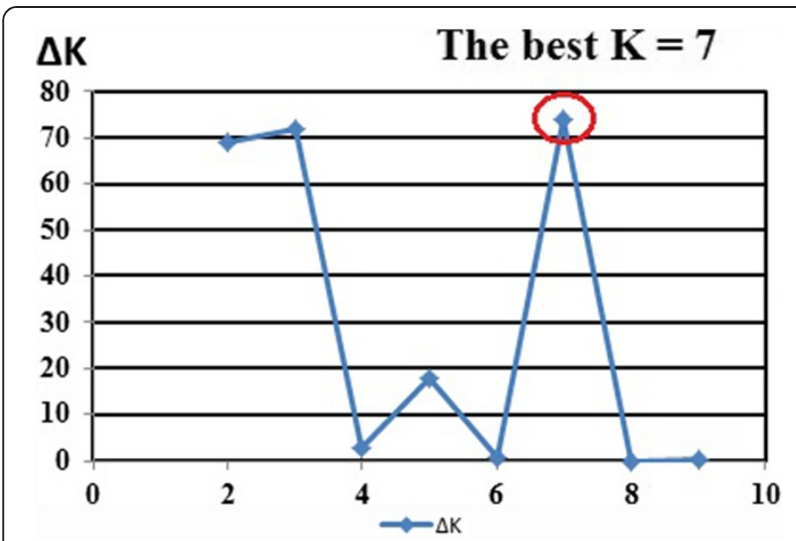

Figure 5 The second order statistics $(\Delta \mathrm{K})$ developed by Evanno (2005) for STRUCTURE in order to determine the number of subpopulations identified the optimal value for $K$. there is no such a distinctive population among the populations analysed in this study. This might be because of there is no any sample from this population among the analysed populations or that might be extinct in the evolutionary history of subspecies populations. Therefore, some individuals are still carrying on the genetic material on their genetic background.

\section{Cluster analysis (UPGMA)}

In the dendrogram, there are two main groups (Figure 4). All the populations except, population $S$ clustered together in the first main group, while population $S$ (I. glauca ssp. sivasica) clustered in the second main group. In the first main group, population AA (I. glauca ssp. galatica) separated clearly from rest of the populations in the first subgroup. In the second subgroup populations clustered into further subgroups. The populations AG1 (I. glauca ssp. glauca) and AG2 (I. glauca ssp. galatica), populations AB (I. glauca ssp. glauca) and ANP (Isatis glauca ssp. galatica), and population AI (I. glauca ssp. glauca) clustered together in the second subgroup. In third subgroup, population K (Isatis glauca ssp. galatica) and E (Isatis glauca ssp. galatica) clustered together.

\section{Principal components analysis (PCA)}

The three extracted principal components according to PCA, explained $85.62 \%$ of the genetic variation (Table 2). The first component, which accounted for $37.06 \%$ of the total variance, was formed by $P, A, H e$, and $A L$ (Additional file 7: Table S7). The second component, representing $29.49 \%$ of the total variance, was formed by $N, L N$, and $R A$, while the third component represented $19.06 \%$ of the total variance, which composed of $L A, T$, and $H U$.

\section{Principal coordinates analysis (PCoA)}

The three coordinates, which obtained according to the PCoA, explained $29.23 \%$ of total variation. The first axis (Eigen vector) displayed $11.96 \%$ of the variance, while the second axis (Eigen vector) and the third axis (Eigen vector) showed $9.41 \%$ and $7.85 \%$ of the variance respectively (data not shown). The codes of 67 accessions are plotted according to the first and the second axis that corresponded to different regions, from where nine $I$. glauca subspecies populations collected (Figure 3). The accessions from populations $\mathrm{AA}, \mathrm{E}, \mathrm{K}$ and $\mathrm{S}$ seperated clearly, the accessions from populations AB, AG1, AG2, $\mathrm{AI}$ and ANP were clustered in the same region.

\section{Multiple regression analysis}

We employed the multiple regressions (MR) to determine AFLP allelic diversity. The results of MR analysis showed that the combination of altitude, latitude, longitude, temperature, humidity, and rainfall accounted for a considerable proportion of the variation observed in AFLP 


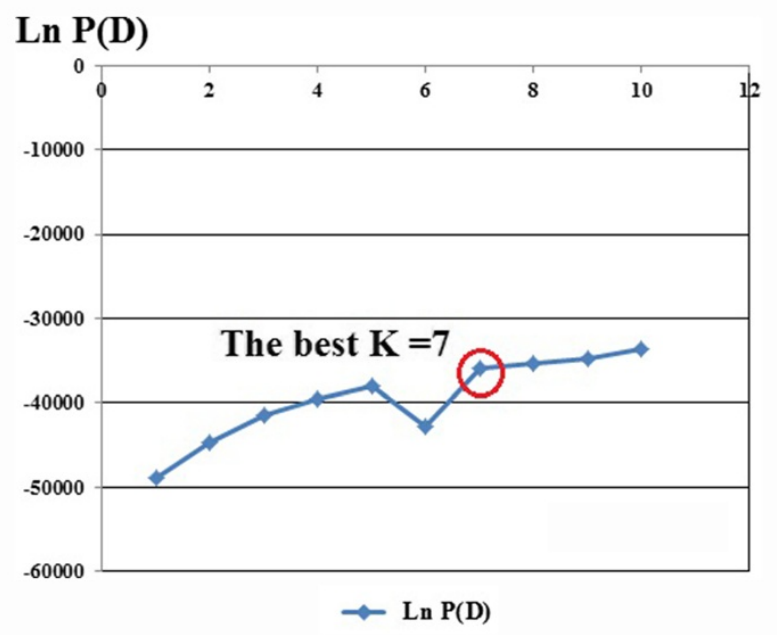

Figure 6 The ad hoc procedure described by Pritchard et al. (2000) to determine the number of subpopulations identified the optimal value for $K$.

fragments diversity (Table 3). When combined, these six variables had effects on the variances of the mean proportion of polymorphic locus $(92.8 \%)$, the mean frequency of alleles $(74.9 \%)$, and the mean genetic diversity (74.9\%); Overall, MR results indicated that climatic and geographic variables in combination with each other affected genetic diversity at a considerable level in Turkish Isatis glauca ssp. populations.

\section{Discussion}

The AFLP technique is a reliable method, which combines the reliability of RFLPs and the power of PCR in a

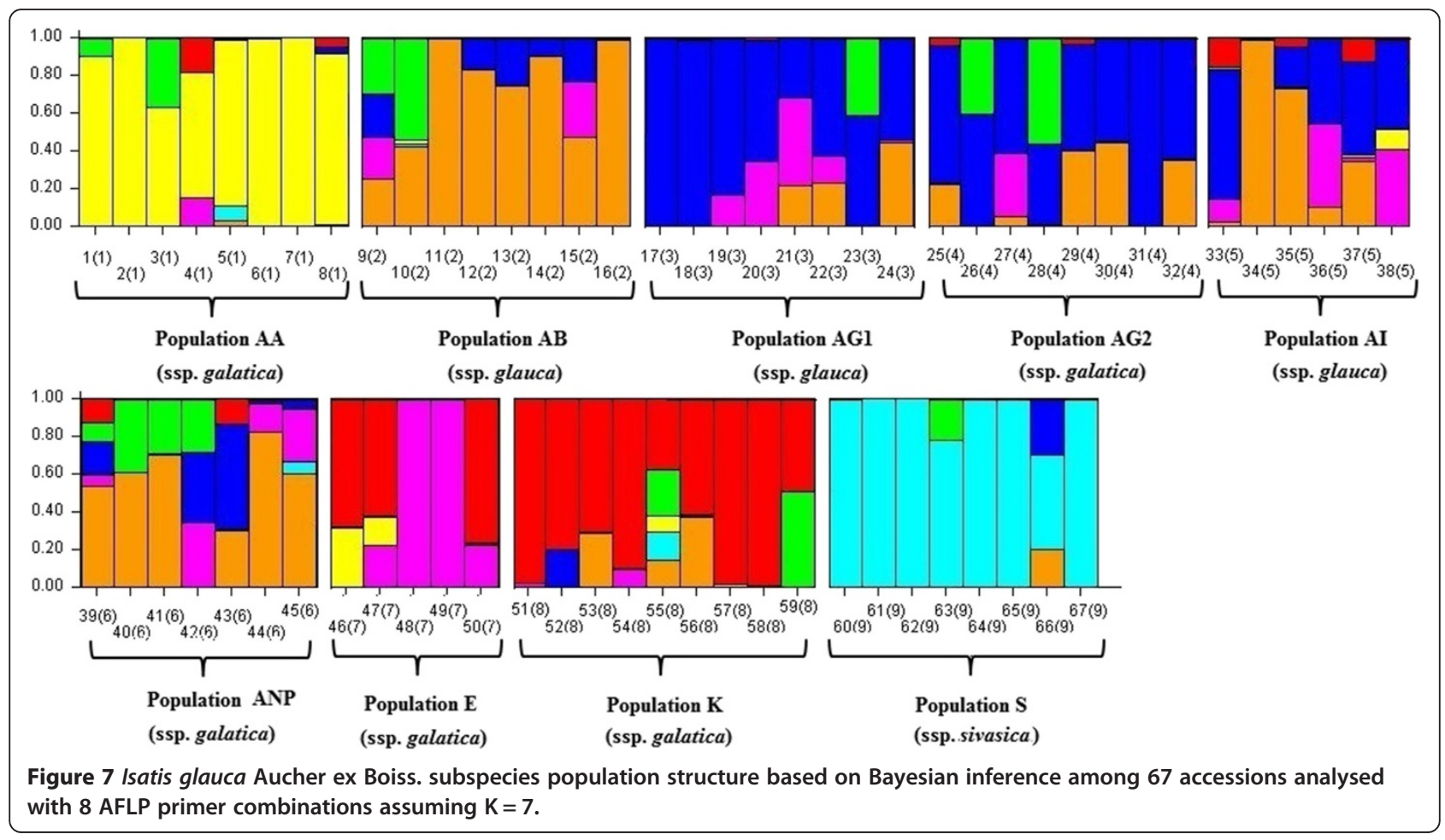


Table 2 Total variance explained by principal component analysis (PCA) was performed by using data of sample size $N$, genetic indices $(P, A$, and $H e)$, climatic $(T, R A$, and $H U)$, and geographical $(A L, L A$, and $L N)$ as variables according to Pearson's correlation (one-tailed) matrix with Eigen values, percentage of variance and cumulative percentage of variance

\begin{tabular}{llll}
\hline Component & Eigen value & Variance (\%) & Cumulative variance (\%) \\
\hline 1 & 3.72 & 37.15 & 37.15 \\
2 & 2.95 & 29.45 & 66.59 \\
3 & 1.90 & 19.03 & 85.62 \\
\hline
\end{tabular}

single method (Krumm et al. 2008) to produce highly polymorphic markers, which are used to analyse genetic diversity in plants. Garcia et al. (2004) reported that AFLP seemed to be the most appropriate molecular essay for fingerprinting and analysing genetic relationships among tropical maize inbred lines with high accuracy. It generates fingerprints of DNA from any origin or complexity (Vos et al. 1995) and produces high number of polymorphic loci. By this way, it overcomes the loss of information because of its dominance (Gerber et al. 2000) was the main reason for giving preference to AFLP method. Taking into account, the results of this study, the AFLP molecular markers could be used effectively to distinguish $I$. glauca subspecies in agreement with Gilbert et al. (2002) and Spataro et al. (2007).

When we compared the results of this study having 793 polymorphic loci, and $98.5 \%$ polymorphism, using 8 AFLP primer combinations on 67 accessions, with previous studies (Gilbert et al. 2002; Spataro et al. 2007), it was observed that this study reported a greater polymorphism among nine Turkish Isatis glauca subspecies populations. The genetic data analysis provides important information regarding genetic structure of the populations. This methodology also helps in screening the populations for genetic diversity within and among populations. The populations $\mathrm{E}$ and $\mathrm{K}$ displayed the higher values of genetic diversity. Population S, being a remote population to the rest of the populations, showed the least genetic diversity. The geographic distance may prevent

Table 3 Displaying the effects of eco-geographical factors on genetic indices by multiple regression analysis (Abbreviations: Dependent variable DV, independent variable IV, coefficient of multiple regression $\mathrm{R}^{2}$, proportion of polymorphic locus $P$, the mean number of allele $A$, the mean value of genetic diversity $\mathrm{He}$, temperature $T$, rainfall $R A$, humidity $H U$, altitude $A L$, latitude $L A$ and longitude $L N$ )

\begin{tabular}{lll}
\hline DV & $\mathbf{R}^{\mathbf{2}}$ & $\mathbf{I V}$ \\
\hline$P$ & 0.928 & $T, R A, H U, A L, L A$, and $L N$ \\
$A$ & 0.749 & $T, R A, H U, A L, L A$, and $L N$ \\
He & 0.749 & $T, R A, H U, A L, L A$, and $L N$ \\
\hline
\end{tabular}

gene transfer via pollination or other types of transfers. In addition, ecogeographical conditions in Sivas, where the population $\mathrm{S}$ collected are harder compared to other locations, from which the other populations collected. In addition observation of high number of unique alleles in population $\mathrm{S}$ displayed that ecogeograhical conditions might have effecs on the adaptation of different genotypes and causing the genetic differentiation in the population S.

AFLP fragment analysis indicated that the primer combinations E39XM40, E36XM34 and E36XM33 amplified more present fragments compared to other primer combinations. However, amplification of fragments by primer combinations varied according to populations. In general the lowest amplified present fragments were observed in population AI that had the lowest polymorphic locus and also lower genetic diversity. According to STRUCTURE analysis results, all individuals, except one are hybrid plants in population AI. This might cause the decrease in amplified fragments. During the hybridisation process, the members of the population AI might have lost some fragments. The population AI most probably inhabited in the area in the recent past according to previous field observations (personel communication with Şinasi Yıldırımlı 2013). According to fragment analysis, the highest number of present fragments were observed in population AA from Ankara/Ayaş. STRUCTURE analysis results indicated that accessions formed a distinctive and stable population structure for population AA. Although, high number of fragments were amplified, low level of genetic diversity was observed. There might be low or no gene flow with other populations due to geographic distance or some other reasons. Therefore, observed homozygosity might be higher than the other populations analysed in this study. We also considered that anthropogenic stresses might have important role on the level of genetic diversity observed in population AA. There is a paper factory in the area and also the plants generally grow on the highway road sides. These factors might cause to reduce genetic diversity in the population. On the other hand amplification of higher number of present fragments might refer that accesions from the population AA that still contain genetic upload of the original population of ssp. galatica in the area.

In outcrossing populations, a higher genetic variation is observed within than among populations or subpopulations (Hamrick and Godt 1990). The finding of this study showed that the gene diversity within-populations (0.76) were much larger compared to the gene diversity (0.24) between-populations is in agreement with Hamrick and Godt (1990) and Spataro et al. (2007). Although to date there is no report of detailed research about the breeding system of I. glauca as in the case of I. tinctoria (Spataro et al. 2007), these results might indicate that $I$. glauca is an outcrossing species. 
The presence and frequency of unique alleles reveal useful and important information about the differentiation in genetic structure of a population. The new alleles in a population exist because of mutations and if they have ability to adapt to their environment, they have a chance to be fitted in the population gene pool. In this study, the population $S$ had a large number (12) of unique alleles, which had frequencies higher than 0.05 . The population $\mathrm{S}$ is geographically distant from the rest of the populations analysed in this study. Therefore, existed unique alleles in populations will drive genetic differentiation between populations as it was observed between population $S$ and the other populations in this study.

Unique alleles have potential as favourable genes for tolerance to severe conditions, especially at higher altitudes (Mondini et al. 2010). The number and frequency of unique alleles have important features, which may be used for improvement of cultivated forms. Isatis L. is economically important plant especially for natural dyestuff beside its medicinal uses. The unique alleles found in I. glauca ssp. populations as molecular markers might be an indication of desirable traits, which can be used in the future breeding programs of Isatis L. plant species.

In the Brassicaceae, hybridization, introgression and hybrid speciation are reported as significant evolutionary forces (Marhold and Lihová 2006). Interspecific gene flow and hybridization promote evolution and species diversity of some genera, e.g. hybrids in Rorippa, as reported by Bleeker and Hurka (2001); Bleeker (2003); Schranz et al. (2005); C. $x$ insueta Urbanska and $C$. schulzii, (Urbanska et al. 1997) (cited in Marhold \& Lihova, 2006) and causes genetic variation (Marhold and Lihová 2006). In breeding programs, landraces or wild relatives have desirable traits such as resistance to cold, drought etc., have been used for improvement of cultivated plants (Du et al. 2009). By this way, transfer of favourable genes/gene complexes from wild allies to cultivated plant gene pools could be possible. However, in most species, incompatibility barriers between wild forms and cultivated forms usually resulted with observation of low fertility in F1 generations that constraint the possible transfer of desirable traits (Inomata, 1993; Rieseberg et al. 1995; Shivanna, 1996; Choudhary and Joshi 2001: cited in Du et al. 2009). Therefore, intertribal somatic hybrids between Brassica napus and I. indigotica (Du et al. 2009), between Brassica rapa and Raphanus sativus with dye and medicinal plant I. indigotica ( $\mathrm{Tu}$ et al. 2008), and between Brassica rapa and I. indigotica (Tu et al. 2008) assessed to overcome genetic barriers by previous researchers. If intertribal hybridization is possible under control of breeders, the possibility to see natural hybrids among Isatis L. species or subspecies in the nature should be the expected case.
Isatis L. species from the Brassicaceae, displays morphological polymorphism and these morphological differences are often masked, even in fruits, which display the most valuable diagnostic features (Davis 1965; Hedge 1968; Jafri 1973: cited in Moazzeni et al. 2007). These variations indicate that hybridization is playing a significant role in the evolution of the genus Isatis L. (Moazzeni et al. 2007). The outcrossing mating system, associated with the perennial habit and vegetative reproduction is a significant factor for hybridization, constitution, and emplacement of the polyploids (Ančev 2006). Consequently, the great morphological (Görgülü et al. 2013) and genetic variation observed in subspecies of I. glauca in this study might be related to hybridization process. This was confirmed with the STRUCTURE analysis results, which showed that in all populations hybrid individuals were observed. Particularly, hybridisation was observed extensively in populations AG1, AG2, AI, and ANP.

According to UPGMA, PCoA and STRUCTURE analysis results, the population $\mathrm{S}$ was clustered as a distant population to the rest of the populations. Also, the genetic distances between population $S$ and rest of the populations were quite high (Data not shown). This might show that formation of I. glauca ssp. sivasica is genetically differentiated obviously more than the rest of the subspecies populations analysed in this study. If the unique AFLP fragments detected in only one subspecies, were extracted, cloned, and sequenced to prepare specific primers, which might be used for simple diagnostics PCR assay of large-scale samples to identify species/subspecies or landraces (Gilbert et al. 2002).

According to the results of this study and previous studies (Yıldırımlı 1988; Görgülü et al. 2013), we suggested that Ankara/Ayaş (population AA) was the germplasm centre of I. glauca ssp. galatica. Some genotypes from Ankara/Ayaş (pop AA) migrated through Ankara/Polatlı (population ANP) and Eskişehir (population E) (Figure 2). On the other hand, some genotypes from Ankara/Ayaş (pop AA) migrated through Ankara/Gölbaş11 (AG1), Ankara/Gölbaşı2 (AG2) and Ankara/Incek (AI) and Konya (population K). We also considered that Ankara/Beytepe was the germplasm centre of I. glauca ssp. glauca (Yıldirimll 1988). The genotypes migrated from population $A B$ through the area, where the populations AG1, AG2, AI, and ANP were collected. By this way ssp. galatica and ssp. glauca populations are overlaped in that area causing to a hybrid zone formation for I. glauca subspecies.

The populations from Eskişehir (E) and Konya (K) have distinctive population structures now and they can be recognised as the varieties of I. glauca ssp. galatica. The gene flow rates between the population ANP and the populations AG1, AG2, and AI seemed to be considerably high. Therefore, in populations AI and ANP all individuals except, one in pop AI, were hybrids. 
The mutations and recombinations generates variation, which underpin genetic diversity in a population. However, selection, genetic drift and gene flow may play an important role in the genetic diversity of particularly in small size populations. The selection might be natural or artificial as it was observed in cultivated crop plant species (Suneson 1960; Frankel 1977; Nevo et al. 1984; Brown 1988; Hamrick et al. 1992: cited in Rao and Hodgkin 2002). Despite the mutations and recombinations raise the genetic diversity as evolutionary frorces in a population, the amount of molecular variation observed in this study can not be attributed to only these forces. PCA and multiple regression analysis represented the effects of environmental components. According to PCA, the environmental factors accept $L A$ and $A L$, mainly contributed to the second and third components. The sum of those components is $48.55 \%$. In addition, multiple regression analysis displayed that when all environmental factors combined they had great effect on the genetic data $(P, A$ and $H e)$. These results displayed that natural selection might play important role in genetic diversity of I. glauca ssp. populations.

During the field studies, it was noticed that population sizes of the I. glauca subspecies were quite small (data not shown). Plants usually grow on the highway road sides, which negatively effect the population size because, the construction of new highways or extending road widths, remove some plant genotypes from those places or they have to move inner sides or different niches (personal communications with Şinasi Yıldırımlı 2013). Anthropogenic stressess may result in genotypes, which have desirable traits such as drought tolerance, climatic changes, etc. to be disappeared and may cause to the genetic drift or bottleneck effect in the germplasms of I. glauca subspecies populations.

Isatis L. was economically an important plant during the Roman times in both Europe and Asia (Guarino et al. 2000). Recently, an increased interest into natural dye products in textile industry raised attention to Isatis L. as an economically important plant once again. The leaves of Isatis subspecies synthesise indoxyl-forming substances, which are indican (Schunk 1855) and isatan B Beijerinck (1900), when they are exposed to the air, reflect the blue compound, indigo (Epstein et al. 1967; Gilbert et al. 2002), which is used in dying. In ancient times I. tinctoria L. (woad) was used for large scale indigo production in Europe. However, according to some recent phytochemical studies (Gilbert et al. 2002; Kizl 2006; Akar 2006) I. glauca can also be used for indigo production. Although it was not used for large scale production, recent studies indicated that it had great potential for the production of indigo. I. glauca ssp. iconia, I. glauca ssp. galatica and I. glauca ssp. sivasica are endemic plant species of Turkey. I. glauca ssp. glauca is native to Lebanon, Syria, Iran, and Transcaucasia (Tübives 2013; Yıldırıml 1988). When breeding programs for $I$. glauca are planned in future, the populations, which have high genetic diversity has more potential for breeding programs. Therefore, the genotypes, from those populations might produce high quality and amount of indigo, and have resistance to environmental stresses factors, such as fungi, bacteria, climatic, and drought, etc. should be selected for cultivation, and the promotion of large scale indigo production.

Evaluating germplasm of genetic resources is an important issue for effective conservation of plant genetic resources. Loveless and Hamrick (1984) reported that the genetic variation in plant populations is structured in space and time. What the extent of genetic diversity and its distribution in a species, it is shaped in which way are the requirements prior to determine what to conserve, and where and how to conserve it (Rao and Hodgkin 2002). Most of the molecular markers are used to determine genetic diversity and construction of genetic distances and physical map. Correlation between expression of a useful trait and a linked molecular marker could be used to construct a genetic linkage map by placing many monogenic and polygenic traits within specific regions of the plant genome (Mondini et al. 2010). Breeders may plan appropriate breeding programs for the marker assisted selection of those quality genes and introgression of these genes to develop standard varieties, which can then be used for large scale production (Gilbert et al. 2002).

\section{Conclusion}

Compared to traditional taxonomy, which is based on morphological characters, molecular tools are used to explain taxonomy, brings in new insights into the phylogeny and taxonomy of many plant groups (Rao and Hodgkin 2002). This is the first study, in which molecular techniques were used to determine the genetic diversity and genetic differentiation among subspecies populations of I. glauca from Turkey.

The main conclusions of this study are as followed;

i. The results of this study showed that AFLP molecular markers could be used effectively to distinguish I. glauca subspecies.

ii. According to molecular data, the UPGMA, PCoA and STRUCTURE analysis, results showed that the accessions from the population $\mathrm{S}$ was clustered as a remote population to the rest of the populations. Populations AA, AB, E, K and S had distinctive population structures.

iii. It is suggested that the population AA is the origin of subspecies I. glauca ssp. galatica germplasm 
center, while the population $\mathrm{AB}$ was the origin of subspecies I. glauca ssp. glauca. germplasm center.

iv. The populations from Eskişehir (E) and Konya (K) were recognised as the varieties of I. glauca ssp. galatica.

v. Ankara province might be the area, where species Isatis glauca Aucher ex Boiss. originated.

vi. The genetic information obtained in the present study will assist to acquire more information about the population genetic structure, the basis for speciation or subspecies formation in Isatis glauca species and its taxonomy. Consequently, the subspecies and their varieties will be allocated taxonomically in appropriate way.

\section{Additional files}

Additional file 1: Table S1. Accession numbers (AN), population codes (PC), the province, where the accessions were collected and subspecies name of the accessions analysed in this study. Accession numbers were given by Professor Dr. Sinasi Yıldırımlı. First two letters represent the population code, which the accession belongs to it. The first number represent collection year and the second number(s) represents the accession number assigned.

Additional file 2: Table S2. The primers and adaptors used in this study (Abbreviations: Primer code PR.C, EcoR I E, and Mse I M).

Additional file 3: Table S3. Primer combinations used in this study; EcoR I primers, labelled with FAM and VIC florescent dye and Mse I primers unlabelled (Abbreviations: Fluorescent label FL, EcoR IE, and Mse | M).

Additional file 4: Table S4. Selective PCR amplification program, used in this study.

Additional file 5: Table S5. Climatic (Temperature T, Humidity HU, and Rainfall RA) data of the places, where the populations were collected (Population code PC).

Additional file 6: Table S6. Private alleles observed in studied nine Turkish Isatis glauca subspecies populations.

Additional file 7: Table S7. Component matrix of variables and their contributions to principal components (Abbreviations: Number of polymorphic locus $P$, average number of allele $A$, average number of allele per polymorphic locus AP, genetic diversity $H e$, temperature $T$, rainfall $R A$, humidity $H U$, altitude $A L$, latitude $L A$ and longitude $L N$ ).

\section{Competing interests}

The authors declare that they have no competing interests.

\section{Authors' contributions}

EG carried out experimental and field studies, and scored the data. ÖÖ designed the study and performed the statistical analysis. She has involved in drafting the manuscript. SY carried out field studies and made identification of plants, collected from the study fields. All authors read and approved the final manuscript.

\section{Authors' information}

EG is doing her PH.D at Hacettepe University in Ankara, Turkey. ÖÖ is an assistant professor at Hitit University, Faculty of Art and Science, Department of Biology, Çorum, Turkey.

ŞY is a professor at Hacettepe University, Faculty of Science, and Department of Biology in Ankara, Turkey.

\section{Acknowledgement}

This is a part of Masters Thesis of Elcin Görgülü and supported by a grant which was provided by the Scientific Research Projects Department (BAP) of Hitit University with the project number FEF03.11.001. The authors are also grateful to Prof. Dr. Hakan Özkan for facilitating AFLP analyses, in his lab at the Department of Field Crops, Faculty of Agriculture, Cukurova University, Adana, Turkey. We would like to thank to assistant professor Muhammet Şakiroğlu at Kafkas University, Kars, in Turkey for his contributions about the evaluating the STRUCTURE analysis results.

\section{Author details}

${ }^{1}$ Department of Biology, Faculty of Art and Science, Hitit University, Ulukavak Mah. Çiftlik Çayııı Cd. No: 61, Çorum, Turkey. ${ }^{2}$ Department of Biology, Faculty of Science, Hacettepe University, Ankara, Turkey.

Received: 5 August 2013 Accepted: 14 October 2013

Published: 4 November 2013

\section{References}

Akar D (2006) Investigations on determination of dyeing properties and dyestuffs content of some Isatis species, which are distributed widely in eastern Mediterranean region, Ph.D. Dissertation. Sütçü Imam University, Kahramanmaraş, Turkey (in Turkish)

Al-Shehbaz IA, Beilstein MA, Kellog EA (2006) Systematics and phylogeny of the Brassicaceae (Cruciferae): an overview. Plant Syst Evol 259:89-120

Ančev M (2006) Polyploidy and hybridization in Bulgarian Brassicaceae: distribution and evolutionary role. Phytologia Balcanica 12(3):357-366

Beijerinck MW (1900) Further researches on the formation of indigo from the woad. Proc K Akademie van Wetenschappen TE Amsterdam 3:101-116

Bleeker W, Hurka H (2001) Introgressive hybridization in Rorippa (Brassicaceae): gene flow and its consequences in natural and anthropogenic habitats. Mol Ecol 10:2013-2022

Bleeker W (2003) Hybridization and Rorippa austriaca (Brassicaceae) invasion in Germany. Mol Ecol 12:1831-1841

Brown AHD (1988) The genetic diversity of germplasm collections. In: Fraleigh B (ed) Proceedings of a Workshop on the Genetic Evaluation of Plant Genetic Resources, Toronto, Canada (pp 9-11). Research Branch, Agriculture Canada, Toronto

Choudhary BR, Joshi P (2001) Crossability of Brassica tournefortii and B. rapa, and morphology and cytology of their F1 hybrids. Theor Appl Genet 102:1123-1128

Davis PH (1965) Isatis. In: Davis PH (ed) Flora of Turkey and the East Aegean Islands, (Vol. 1, 1-567). Edinburgh University Press, Edinburgh

Du X, Ge X, Yao X, Zhao Z, Li Z (2009) Production and cytogenetic characterization of intertribal somatic hybrids between Brassica napus and Isatis indigotica and backcross progenies. Plant Cell Rep 28:1105-1113

Epstein E, Nabors MW, Stowe BB (1967) The origin of indigo in woad. Nature 216:547-549

Evanno G, Regnaut S, Goudet J (2005) Detecting the number of clusters of individuals using the software STRUCTURE: a simulation study. Mol Ecol 14:2611-2620

Frankel OH (1977) Natural variation and its conservation. In: Muhammed A, Aksel $R$, von RC B (eds) Genetic Diversity in Plants (pp. 21-44). Plenum Press, New York

Garcia AAF, Benchimol LL, Barbosa AMM, Geraldi IO, Souza CL Jr, de Souza AP (2004) Comparison of RAPD, RFLP, AFLP and SSR markers for diversity studies in tropical maize inbred lines. Genet Mol Biol 27(4):579-588

Gilbert KG, Garton S, Karam MA, Arnold GM, Karp A, Edwards KJ, Cooke DT, Barker JHA (2002) A high degree of genetic diversity is revealed in Isatis spp. (dyer's woad) by amplified fragment length polymorphism (AFLP). Theor Appl Genet 104:1150-1156

Gerber S, Mariette S, Streiff R, Bodénès C, Kremer A (2000) Comparison of microsatellites and amplified fragment length polymorphism markers for parentage analysis. Mol Ecol 9:1037-1048

Görgülü E, Özbek Ö, Yıldııımlı ş (2013) Determination of morphological variation in subspecies of Isatis glauca Aucher ex Boiss. from Central Anatolia. Plant Syst Evol 299:827-840. doi:10.1007/s00606-013-0765-2

Guarino C, Casoria P, Menale B (2000) Cultivation and use of Isatis tinctoria L. (Brassicaceae) in Southern Italy. Econ Bot 54(3):395-400

Hamrick JL, Godt MJW (1990) Allozyme diversity in plant species. In: Brown AHD, Clegg MT, Kahler AL, Weir BS (eds) Plant population genetics, breeding and genetic resources (pp. 43-63). Sinauer Associates, Sunderland

Hamrick JL, Godt MJW, Sherman-Broyles SL (1992) Factors influencing levels of genetic diversity in woody plant species. New Forests 6:95-124

Hartl DL, Clark AG (1997) Principles of Population genetics, $3^{\text {rd }}$ eds. Sinauer Associates, Sunderland 
Hedge IC (1968) Lepidieae. In: Rechinger KH (ed) Flora Iranica 57: 63-122). Akademische Druck- und Verlagsanstalt, Graz

Inomata N (1993) Crossability and cytology of hybrid progenies in the cross between Brassica campestris and three wild relatives of $B$. oleracea, $B$. bourgeaui, B. cretica and B. montana. Euphytica 69:7-17

Jafri SMH (1973) Brassicaceae. In: Nasir E, Ali SI (eds) Flora of West Pakistan 55:1-308. University of Karachi, Karachi

Kidwell KK, Osborn TC (1992) Simple plant DNA isolation procedures, Plant Genomes: Methods for Genetic and Physical Mapping (81-13). Kluwer Academic Publishers, The Netherlands

KIzI S (2006) Morphological and agronomical characteristics of some wild and cultivated Isatis species. J Cent Eur Agric 7(3):479-484

Krumm JT, Hunt TE, Skoda SR, Hein GL, Lee DJ, Clark PL, Foster JE (2008) Genetic variability of the European corn borer, Ostrinianu bilalis, suggests gene flow between populations in the Midwestern United States. J Insect Sci 8 (72):1536-2442

Lewis PO, Zaykin D (2001) Genetic data analysis: computer program for the analysis of allelic data. Version $1.0(\mathrm{~d} 16 \mathrm{c})$. Free program distributed by the authors over the internet from http://www.eeb.uconn.edu/people/plewis/ software.php

Loveless MD, Hamrick JL (1984) Ecological Determinants of Genetic Structure in Plant Populations. Ann Rev Ecol Syst 15:65-95. doi:10.1146/annurev. es.15.110184.000433

Marhold K, Lihová J (2006) Polyploidy, hybridization and reticulate evolution: lessons from the Brassicaceae K. Plant Syst Evol 259:143-174. doi:10.1007/ s00606-006-0417-x

Misırdalı H (1985) Taxonomic and cytological investigations on the species of Isatis L., grown in the Eastern and South Eastern Anatolia and over the regions of Eastern Mediterranean., Project No: TBAG-535, p.139 (in Turkish)

Moazzeni H, Zarre S (2006) On the Circumscription of Isatis tinctoria L. (Brassicaceae) in Iran. Turk J Bot 30:455-458

Moazzeni H, Zarrea S, Al-Shehbaz IA, Mummenhoff K (2007) Seed-coat microsculpturing and its systematic application in Isatis (Brassicaceae) and allied genera in Iran. Flora 202:447-454

Moazzeni H, Zarre S, Al-Shehbaz IA, Mummenhoff K (2010) Phylogeny of Isatis (Brassicaceae) and allied genera based on ITS sequences of nuclear ribosomal DNA and morphological characters. Flora 205:337-343

Mondini L, Farina A, Porceddu E, Pagnotta MA (2010) Analysis of durum wheat germplasm adapted to different climatic conditions. Annu Appl Biol 156(2):211-219

Nei M (1973) Analysis of gene diversity in subdivided populations. Proc Natl Acad Sci USA 70:3321-3323

Nei M (1978) Estimation of average heterozygosity and genetic distance from a small number of individuals. Genetics 8:583-590

Nevo E, Beiles A, Ben-Shlomo R (1984) The evolutionary significance of genetic diversity: ecological, demographic and life history correlates. Lecture Notes of Biomath 53:13-21

Pritchard JK, Stevens M, Donnelly P (2000) Inference of population structure using multilocus genotype data. Genetics 155:945-959

Rao RV, Hodgkin T (2002) Genetic diversity and conservation and utilization of plant genetic resources. Plant Cell, Tissue Organ Cult 68:1-19

Rieseberg LH, Randal LC, Seiler GJ (1995) Chromosomal and genetic barriers to introgression in Helianthus. Genetics 141:1163-1171

Rocha L, Carvalho C, Martins S, Braga F, Carnide V (2011) Morpho-agronomic characterization and variation of indigo precursors in woad (Isatis tinctoria L.) accessions. Plant Genetic Resources: Characterization and Utilization 9(2):206-209

Schranz ME, Dobes ${ }^{*}$ C, Koch MA, Mitchell-Olds T (2005) Sexual reproduction, hybridization, apomixis, and polyploidization in the genus Boechera (Brassicaceaea). Am J Bot 92:1797-1810

Schunk E (1855) On the formation of indigo blue (part I). Philosophical Magazine and J Sci Series 4(10):74-95

Shivanna KR (1996) Incompatibility and wide hybridization. In: Chopra VL, Prakash S (eds) Oilseed and vegetable brassicas: Indian perspective (pp. 77-102). Oxford and IBH Pub, New Delhi

Spataro G, Taviani P, Negri V (2007) Genetic variation and population structure in Eurasian collection of Isatis tinctoria L. Genet Resour Evol 54:573-584

Spataro G, Negri V (2008) Adaptability and variation in Isatis tinctoria L.: a new crop for Europe. Euphytica 163:89-102

Suneson CA (1960) Genetic diversity- a protection against diseases and insects. Agron J 52:319-321
Tu Y, Sun J, Liu Y, Ge X, Zhao Z, Yao X, Li Z (2008) Production and characterization of intertribal somatic hybrids of Raphanus sativus and Brassica rapa with dye and medicinal plant Isatis indigotica. Plant Cell Rep 27:873-883

Tübives (2013) Turkish Plants Data Service (Tübives), TUBITAK. http://turkherb.ibu. edu.tr/

Tu Y, Sun J, Ge X, Li Z (2009) Chromosome elimination, addition and introgression in intertribal partial hybrids between Brassica rapa and Isatis indigotica. Ann Bot 103:1039-1048

Urbanska KM, Hurka H, Landolt E, Neuffer B, Mummenhoff K (1997) Hybridization and evolution in Cardamine (Brassicaceae) at Urnerboden, Central Switzerland: biosystematic and molecular evidence. PI Syst Evol 204:233-256

Vos P, Hogers R, Bleeker M, Reijans M, van dee Lee T, Barnes M, Frijters A, Pot J, Peleman J, Kuiper M, Zabean M (1995) AFLP: a new technique for DNA fingerprinting. Nucleic Acids Res 23(21):4407-4417

Weir BS (1996) Genetic data analysis II. Sinauer Associates, Sunderland

Wright S (1951) The genetical structure of populations. Annals of Eugenetics 15:323-354

Yıldıımlı ş, Doğan C (1986) Polymorphism in Isatis glauca. VIII. National Biology Proceeding, September, 3-5, Izmir

Yıldırımlı S (1988) Revision of Isatis L. (Curiciferae) genus from west and nort part of Turkey. Turk J Bot 12(3):332-400 (in Turkish)

doi:10.1186/1999-3110-54-48

Cite this article as: Özbek et al.: Genetic diversity in populations of Isatis glauca Aucher ex Boiss. ssp. from Central Anatolia in Turkey, as revealed by AFLP analysis. Botanical Studies 2013 54:48.

\section{Submit your manuscript to a SpringerOpen ${ }^{\odot}$ journal and benefit from:}

- Convenient online submission

- Rigorous peer review

- Immediate publication on acceptance

- Open access: articles freely available online

High visibility within the field

- Retaining the copyright to your article

Submit your next manuscript at $\gg$ springeropen.com 